Disclosure of Interests: Xiaofeng Zeng: None declared, Dongbao Zhao: None declared, Sebastiao Radominski: None declared, MAURO KEISERMAN: None declared, Chang-Keun Lee: None declared, Naomi Martin Employee of: AbbVie employee and may own stock or options, Sebastian Meerwein Employee of: AbbVie employee and may own stock or options, Yunxia Sui Employee of: AbbVie employee and may own stock or options, Won Park: None declared DOI: 10.1136/annrheumdis-2021-eular.1807

\section{AB0261 A MULTINATIONAL, PROSPECTIVE, OBSERVATIONAL STUDY IN PATIENTS WITH RHEUMATOID ARTHRITIS RECEIVING BARICITINIB, TARGETED SYNTHETIC OR BIOLOGIC DISEASE-MODIFYING THERAPIES (RA-BE-REAL) - STUDY DESIGN AND BASELINE CHARACTERISTICS}

R. Alten ${ }^{1}$, G. R. Burmester ${ }^{2}$, M. Matucci-Cerinic ${ }^{3}$, J. H. Salmon ${ }^{4}$, P. LópezRomero $^{5}$, W. Fakhouri ${ }^{5}$, I. De La Torre ${ }^{5}$, A. Gentzel-Jorczyk ${ }^{5}$, T. Holzkaemper ${ }^{5}$, B. Fautrel ${ }^{6,7} .{ }^{1}$ University Medicine Berlin, Department of Internal Medicine and Rheumatology, Berlin, Germany; ${ }^{2}$ Charité Universitätsmedizin Berlin, Department of Rheumatology and Clinical Immunology, Berlin, Germany; ${ }^{3}$ University of Florence, Division of Rheumatology, Florence, Italy; ${ }^{4} \mathrm{CHU}$ de Reims, Traumatologie-Orthopédie, Reims, France; ${ }^{5}$ Eli Lilly and Company, Lilly Corporate Center, Indianapolis, United States of America; ${ }^{6}$ Sorbonne University, Department of Rheumatology, Paris, France; ${ }^{7}$ Pierre Louis Institute of Epidemiology and Public Health, PEPITES Team, Paris, France

Background: Baricitinib (BARI) is a JAK1-2 inhibitor approved for the treatment of adults with moderately to severely active rheumatoid arthritis (RA). RA-BEREAL is a 3-year, prospective, observational study of adult RA patients (pts) evaluating adherence to treatment in clinical practice.

Objectives: To describe pt and disease characteristics of pts enrolling into RA-BE-REAL in 5 European countries.

Methods: The primary endpoint of RA-BE-REAL is time until discontinuation of initial treatment for all causes (excluding sustained clinical response) over a 24-month (M) period. Secondary endpoints include clinical and pt reported outcomes, healthcare resource utilization and treatment patterns over a $36 \mathrm{M}$ period. Two pt cohorts are assessed: cohort A, started treatment with BARI (2-mg or 4-mg), and cohort B, any other targeted synthetic (ts)DMARDs or biologic (b) DMARD (Fig. 1). Treatment initiation and changes are at the discretion of the pt and physician. Data is collected at baseline and at routine visits $(\sim 3 \mathrm{M}, 6 \mathrm{M}, 12 \mathrm{M}$, $18 \mathrm{M}, 24 \mathrm{M}$ and $36 \mathrm{M})$. Summaries are presented with t-test and chi-square test of independence.

Results: Between October 2018 and March 2020, 1074 adult RA pts were enrolled from France, Germany, Italy, Spain, and UK. In cohort A, $88.2 \%$ of pts are treated with BARI 4-mg. At time of enrolment pts in cohort A are more likely to commence treatment as a monotherapy as compared to pts in cohort B who are more likely to commence treatment in combination with csDMARDs $(p<0.001)$. Cohort $A$ are more likely to be older ( 59.2 vs 57.0 , mean years $p=0.009$ ) and have higher Health Assessment Questionnaire-Disability Index (HAQ-DI) scores (1.4 vs $1.3, p=0.03)$. A greater percentage of cohort $A$ pts have received prior treatment with either $1 \mathrm{~b} / \mathrm{tsDMARD}$ (15.3 vs $11.0 \%), 2 \mathrm{~b} / \mathrm{tsDMARD}(20.2$ vs $14.7 \%)$ or $>2$ b/tsDMARD (15.9 vs $12.9 \%$ ), while cohort B are more likely to be treatment naïve ( 61.4 vs $48.5 \%)$. There are no significant differences in other baseline characteristics shown in Table 1.

Conclusion: There are few but potentially clinically important differences between cohorts. Pts in cohort A are more likely to be older, have a longer disease duration, have received prior b/tsDMARD treatment, and are more likely to receive treatment as a monotherapy as compared to pts in cohort $B$.

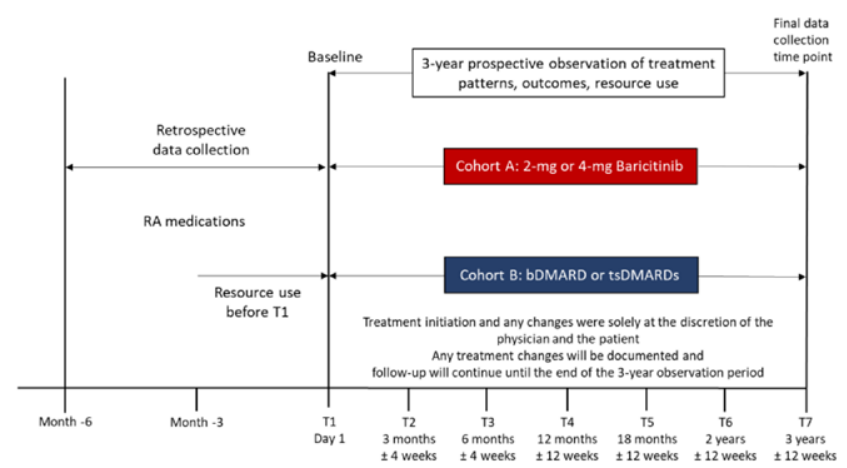

Figure 1. Study Design. Participants entered cohort A or B based on their treatment decision for BARI or another b/tsDMARD, pts in each cohort were with/without concomitant csDMARDs.
Table 1. Patient disposition and baseline characteristics.

\begin{tabular}{|c|c|c|c|c|c|}
\hline & \multirow{2}{*}{$\begin{array}{c}\text { Cohort A } \\
\text { Baricitinib } \\
(n=509)\end{array}$} & \multicolumn{3}{|c|}{ Cohort B } & \multirow{2}{*}{$\begin{array}{c}\text { Overall } \\
(n=1074)\end{array}$} \\
\hline & & $\begin{array}{c}\text { TNFi } \\
(n=338)\end{array}$ & $\begin{array}{c}\text { non-TNFi } \\
(n=161)\end{array}$ & $\begin{array}{l}\text { tsDMARD } \\
(\mathrm{n}=66)\end{array}$ & \\
\hline \multicolumn{6}{|l|}{ Combination Therapy } \\
\hline $\begin{array}{l}\text { with any csDMARD } \\
\text { monotherapy }\end{array}$ & $238(46.8)$ & $231(40.9)$ & $110(19.5)$ & $38(6.7)$ & $617(57.4)$ \\
\hline monotherapy & $271(53.2)$ & $107(18.9)$ & $51(9.0)$ & $28(5.0)$ & 457 (42.6) \\
\hline Values represent $n(\%)$ & $\begin{array}{l}\text { Cohort A } \\
(n=509)\end{array}$ & $\begin{array}{l}\text { Cohort B } \\
(n=565)\end{array}$ & p-value & & $\begin{array}{c}\text { Overall } \\
(n=1074)\end{array}$ \\
\hline Age in years & $59.2(13.2)$ & $57.0(13.9)$ & 0.009 & & $58.0(13.6)$ \\
\hline Disease duration in years & $10.3(9.2)$ & $9.1(9.8)$ & 0.05 & & $9.7(9.5)$ \\
\hline CDAI & $24.1(11.7)$ & $23.9(12.4)$ & 0.75 & & $24.0(12.1)$ \\
\hline Swollen joint count & $5.2(4.8)$ & $4.7(4.9)$ & 0.18 & & $4.9(4.8)$ \\
\hline Tender joint count & $7.3(6.1)$ & $7.8(6.5)$ & 0.19 & & $7.6(6.3)$ \\
\hline PhGA & $5.6(2.0)$ & $5.5(2.1)$ & 0.39 & & $5.6(2.0)$ \\
\hline PGA & $5.9(2.3)$ & $5.8(2.4)$ & 0.49 & & $5.9(2.4)$ \\
\hline Pain VAS & $59.0(23.1)$ & $56.4(24.3)$ & 0.08 & & $57.6(23.8)$ \\
\hline HAQ-DI & $1.4(0.7)$ & $1.3(0.7)$ & 0.03 & & $1.4(0.7)$ \\
\hline $\begin{array}{l}\text { b/tsDMARDs treatment any } \\
\text { time before enrolment; } \\
\text { n (\%) }\end{array}$ & & & $<0.001^{*}$ & & \\
\hline Naïve & $247(48.5)$ & $347(61.4)$ & & & $594(55.3)$ \\
\hline $1 \mathrm{~b} / \mathrm{tsDMARD}$ & $78(15.3)$ & $62(11.0)$ & & & $140(13.0)$ \\
\hline 2 b/tsDMARDs & $103(20.2)$ & $83(14.7)$ & & & $186(17.3)$ \\
\hline$>2 \mathrm{~b} / \mathrm{ts} D M A R D s$ & $81(15.9)$ & 73 (12.9) & & & $154(14.3)$ \\
\hline
\end{tabular}

Values represent mean (SD), unless otherwise stated.b/tsDMARD, biologic/targeted synthetic disease-modifying antirheumatic drug; CDAl, Clinical Disease Activity Index; HAQ-DI, Healthy Assessment Questionnaire-Disability Index; P(h)GA, Patient's (Physician's) global assessment of disease activity; VAS, Visual analogue scale. "chi-square test of independence for comparison of b/tsDMARD treatment received before enrolment.

Acknowledgements: The authors would like to acknowledge Luke Healy for medical writing support.

Disclosure of Interests: Rieke Alten Speakers bureau: Janssen Pharmaceuticals, Eli Lilly and Company, Pfizer Inc., and Galapagos, and Gilead Sciences Consultant of: Eli Lilly and Company, Pfizer Inc., Galapagos NV, and Gilead Sciences, Grant/research support from: Bristol-Myers Squibb, Eli Lilly and Company, Pfizer Inc., Galapagos NV, and Gilead Sciences, Gerd Rüdiger Burmester Speakers bureau: AbbVie, Gilead Sciences, Eli Lilly and Company, and Pfizer Inc., Consultant of: AbbVie, Gilead Sciences, Eli Lilly and Company, and Pfizer Inc., Marco Matucci-Cerinic Speakers bureau: Actelion, Janssen Pharmaceuticals, MSD, Eli Lilly and Company, Biogen Inc., Grant/research support from: MSD, Actelion., Jean-Hugues Salmon: None declared, Pedro López-Romero Shareholder of: Eli Lilly and Company, Employee of: Eli Lilly and Company, WALID FAKHOURI Shareholder of: Eli Lilly and Company, Employee of: Eli Lilly and Company, Inmaculada De La Torre Shareholder of: Eli Lilly and Company, Employee of: Eli Lilly and Company, Anja Gentzel-Jorczyk Employee of: Eli Lilly and Company, Thorsten Holzkaemper Shareholder of: Eli Lilly and Company, Employee of: Eli Lilly and Company, Bruno Fautrel Consultant of: AbbVie, Biogen, Bristol-Myers Squibb, Celgene, Janssen Pharmaceuticals, Eli Lilly and Company, Medac, MSD, NORDIC Pharma, Novartis, Pfizer Inc., Roche, SanofiAventis, SOBI, UCB, Grant/research support from: AbbVie, MSD, Pfizer Inc. DOI: 10.1136/annrheumdis-2021-eular.2035

\section{AB0262 1 CLINICAL EFFICACY OF SWITCHING FROM ORAL TO SUBCUTANEOUS METHOTREXATE IN MANAGEMENT OF RHEUMATOID ARTHRITIS: EXPERIENCE FROM OUT-PATIENT SETTING OF A DISTRICT GENERAL HOSPITAL IN UK}

G. Ansari ${ }^{1}$, A. Nandagudi ${ }^{1}$, A. Bharadwaj ${ }^{1} .{ }^{1}$ Basildon Hospital Mid and South Essex NHS Foundation Trust UK, Rheumatology, Essex, United Kingdom

Background: Methotrexate (MTX) is an anchor drug in the treatment of Rheumatoid arthritis. The literature review has shown that subcutaneous (SC) methotrexate has shown better efficacy, less adverse side effects and better compliance in inflammatory arthritis. Our department modified Inflammatory arthritis pathway in 2018 where all patient with moderate or severe disease are switched from oral to SC Methotrexate injection for improved management.

Objectives: The aim of our study is to review whether switching of oral methotrexate (PO MTX) to subcutaneous methotrexate (SC MTX) helps to improve disease activity in patients with rheumatoid arthritis and avoids the need to introduce biologic therapy.

Methods: We conducted a retrospective audit of patients with rheumatoid arthritis seen between January 2018 to January 2020 recording their age, gender, diagnosis, date of MTX switch and disease activity score 6 months after switching to SC MTX. Significance of change was calculated with test of proportion/chi square test. 